\title{
Evaluation of Phytochemicals, Antioxidant, Antibacterial and Antidiabetic Potential of Alpinia galanga and Eryngium foetidum Plants of Manipur (India)
}

\author{
Tabarak Malik ${ }^{1 *}$, Devendra Kumar Pandey ${ }^{2}$, Priyanka Roy ${ }^{3}$, Annie Okram² \\ 'Department of Biomedical Sciences, College of Health Sciences, Jimma University, Jimma, ETHIOPIA. \\ 2Department of Biotechnology, School of Biosciences, Lovely Professional University, Phagwara-144402, INDIA \\ ${ }_{3}^{3}$ Junior Research Fellow, Defence Research and Development Organisation (DRDO), Defence Institute of Bio Energy Research (DIBER), Haldwani, Uttarakhand, INDIA.
}

\begin{abstract}
Background: Alpinia galanga and Eryngium foetidum are two commonly used traditional aromatic plants of Manipur which is traditionally used in Aroma therapy. Rationale of pharmacological potentials of these plants are still unclear, even if few preliminary studies are available in literature for individual plants. Objective: This study was conducted for comparative assessment of antioxidant, antibacterial, and antidiabetic potential of $A$. galanga and $E$. foetidum. Materials and Methods: The rhizome of $A$. galanga and leaf of $E$. foetidum were extracted in methanol, ethanol and water. Phytochemicals of each extracts of Alpinia galanga and Eryngium foetidum were analyzed. The antioxidant potential of all the extracts was assessed by measuring total phenolic content, total flavonoid content and free radical scavenging potential was assessed by 1,1-diphenyl-2-picrilhydrazyl (DPPH) assay, antibacterial activity was assessed against various pathogenic and nonpathogenic bacteria in vitro by Kirby-Bauer agar well diffusion method and antidiabetic activity was assessed by $\alpha$-amylase inhibition. Results: Both the plant showed presence of all the tested phytochemicals. It was observed that methanolic extracts of both the plants have higher phenolic content than ethanolic and aqueous extracts, however ethanolic extracts
\end{abstract}

E. foetidum shows higher flavonoid contents. Both the plant shows similar DPPH scavenging and metal chelating activity. It was also observed that the antidiabetic potential of $A$. galanga is greater than $E$. foetidum. The methanolic and ethanolic extracts of the plants shows quite similar and good antibacterial potential than the aqueous extracts. Conclusion: The present study suggests that both Alpinia galanga and Eryngium foetidum plants of Manipur could be used as herbal remedies for the treatment of diabetes mellitus as well as managing oxidative stress and oxidative stress related disorders.

Key words: Phytochemicals, Antioxidant, Antibacterial, Antidiabetic, Manipur, A. galangal, E. foetidum.

Corresponding author: Dr. Tabarak Malik, Department of Biomedical science, College of Heaith Science, Jimma university, Jimma, ETHOPIA.

Phone: +91-9915523572

Email:malikitrc@gmail.com

DOI : $10.5530 /$ pj.2016.5.8

\section{INTRODUCTION}

Manipur state is situated at north-eastern region of India geographically distributed from $23^{\circ} 56^{\prime} \mathrm{N}$ to $25^{\circ} 44^{\prime} \mathrm{N}$ and from $93^{\circ} 02^{\prime} \mathrm{E}$ to $94^{\circ} 47^{\prime} \mathrm{E}$. ${ }^{1}$ Manipur is famous for its rich biodiversity of flora and fauna, beautiful environment surrounded by numerous hills and mountains like Imphal valley and for its precious source of medicinal plants. This provides a great opportunity to explore and formulate therapeutic medicines. The phytochemicals present in these therapeutic plants have received a great attention in preventing diseases caused by oxidative stress which releases reactive oxygen species such as singlet oxygen and other free radicals as a result of side-effect of aerobic metabolism. DNA damage, tissue injury, cardiovascular malfunctions, tumour promotion and early ageing like numbers of uncountable disorders includes the involvements of damaging activity of these free radicals. ${ }^{2,3}$ Various indigenous formulations have been produced from many medicinal plants found in this region also successfully used as anti-diabetic and anti-microbial agents. The plants Alpinia galanga and Eryngium foetidum are among them, these plants are not only a source of food, flavour but are also a good source of natural and herbal medicine.

The plant Alpinia galanga is a perennial herb belonging to the Zingiberaceae family. A. galanga commonly known as great galangal also called as Kulanjan in Hindi and Kanghoo in Manipuri. It is distributed throughout the Western Ghats, Gujarat, Mysore, Goa, Manipur, and other Southeast Asian countries. One of the most active compounds found is terpinen-4-ol and also contains alkaloids, saponins, glycosides, terpenoids, phenolics, flavonoids, phytosterols, carbohydrates are important phytoconstituents present in this plant. ${ }^{4}$ Galango flavonoid a newly reported flavonoid was isolated from ethanolic extract of Alpinia galangal. ${ }^{5}$ The rhizome extract of $A$. galanga has been reported to possess several medicinal active ingredient that have a potential of antitumour, antioxidant, antifungal, antibacterial, gastro protective, hypoglycaemic, hypolipidemic, anti-inflammatory substance. ${ }^{6}$ It has been also reported by many researcher that methanolic and aqueous extracts of Alpinia galanga showed significant free radical scavenging activity against DPPH radical and also possess strong superoxide anion scavenging activity as well as metal chelating activity. Moreover the ethanolic extract of galangal was also found to be effective in inhibiting $\alpha$-glucosidase and $\alpha$ amylase (in vitro) as well as a good antimicrobial activity. ${ }^{7,8}$

Eryngium foetidum is another perennial herb of Manipur extensively used as a medicinal and aromatic plant. It belongs to the Apiaceae family and distributed throughout many state of India namely Manipur, Tamil Nadu, Kerala, Karnataka, Assam, Andaman and Nicobar Islands. ${ }^{9}$ The plant is commonly used as home remedies to treat burns, ear ache, fevers, hypertension, constipation, seizures, asthma, stomach ache, worms, infertility complications, snake bites, arthritis, diarrhea and malaria by tribal people of Manipur. ${ }^{10}$ The various bioactive component of E. fotidum was discovered till date includes phenols, flavonoids, tannins and polyphenols. The polyphenolic compounds of E. foetidum acts as anti-inflammatory, hepatoprotective, antioxidant, antithrombotic, anticarcinogenic, free radical scavenger, antimutagenic, antimicrobial and antihyperglycemic activity in vitro against $\alpha$-amylase enzyme. ${ }^{11,12,13}$ E. foetidum leaf extract possesses suppressive effects against proinflammatory mediators. Thus, 
E. foetidum has a high potential to be used as a food supplement to reduce risk of cancer associated with inflammation. ${ }^{14}$

\section{MATERIALS AND METHOD}

\section{CHEMICALS AND REAGENT}

Chloroform, DMSO, Sulphuric acid, Dilute ammonia, Ferric chloride, Hydrogen chloride, Deionised distilled water, Folin-Ciocalteau reagent, Draggendorff's reagent, Sodium carbonate and Gallic acid are used for phytochemical screening and antioxidant assay. Mueller-Hinton broth and agar media are used for antibacterial assay. All the reagent and media were purchased from Hi Media. Starch and $\alpha$-amylase enzyme are used for antidiabetic assay.

\section{INSTRUMENTATION}

Grinder, Water bath, Glass ware (conical flasks, beakers, test-tubs, Petri plates), Micropipette, Gel puncher, Digital balance, Incubator, Laminar Flow hood, Hot air oven, Spectrophotometer, Refrigerator, Autoclave and Micro-wave oven.

\section{PLANT MATERIAL}

The whole plant of Eryngium foetidum and Alpinia galanga were collected from a local area of Imphal, Manipur in December, 2013. The plant samples were identified by the taxonomist at D.M. College of Science, Imphal, Manipur. The rhizome part of the plant A. galanga and leaf of $E$. foetidum were separated and cleaned in running tap water followed by distilled water and dried in shade for 15 days. The parts under study i.e leaf of Eryngium and rhizome of Alpinia were then ground in a coarse powder using grinder and preserved in air-tight containers.

\section{MICROORGANISMS USED}

Bacterial strains analyzed were obtained from IMTECH, Chandigarh (Bacillus megaterium MTCC 8510, Bacillus subtilis MTCC 441, Bacillus flexus MTCC 7024, Staphylococcus aureus MTCC 96, Pseudomonas oleovorans MTCC 617, Klebsiella pneumoniae MTCC 7028, Salmonella enteric MTCC 1164 and Escherichia coli MTCC 723).

\section{EXTRACTION OF PLANT MATERIALS}

The extraction of plant parts was carried out according to the method suggested by Fatope et al. $1993 .{ }^{15}$ In this, $20 \mathrm{~g}$ fine powder of rhizome part of the plant A. galanga and leaf of E. foetidum were percolated at room temperature with $400 \mathrm{ml}$ in methanol for methanolic extraction, in ethanol for ethanolic extraction and in water for aqueous extraction respectively (so as to achieve a solvent extraction in ratio 1:20) in $600 \mathrm{ml}$ screw caped conicals. The conical were screw caped and placed in shaker at room temperature for $24 \mathrm{hrs}$ at $100 \mathrm{rpm}$. After $24 \mathrm{hrs}$ the extracts were filtered using muslin cloth and then re-filtered using Whatman filter paper No. 1. The filtrates were concentrated using water bath at $35-40^{\circ} \mathrm{C}$. The extracts were labeled accordingly and preserved in refrigerator at $4^{\circ} \mathrm{C}$, till further work. Extract was dissolved in Dimethyl sulfoxide (DMSO) to made concentration of the stock solution of $0.5 \mathrm{~g} / \mathrm{ml}$.

\section{PHYTOCHEMICAL SCREENING}

Phytochemical are non-nutritive chemical present in plants that contribute to the medicinal properties of that plant, which have disease preventive properties. Phytochemical screening of different extracts of Alpinia galanga and Eryngium foetidum were carried out according to the methods of Ayoola et al. 2008. ${ }^{16}$ The different plant part extracts prepared were screened for terpenoids, flavonoids, saponins, tannins and phenols respectively:

\section{Test for Terpenoids (Salkowski Test)}

To $0.5 \mathrm{~g}$ of each of the plant part extracts were added with $2 \mathrm{ml}$ of chloroform. Then into it $3 \mathrm{ml}$ of concentrated sulphuric acid was carefully added, to form a layer. A reddish-brown colouration of the interface indicated the presence of terpenoids.

\section{Test for Flavonoids}

In $0.5 \mathrm{ml}$ of filtrate of each of the plant parts extracts, $5 \mathrm{ml}$ of dilute ammonia was added, followed by addition of $1 \mathrm{ml}$ of concentrated sulphuric acid to it. The presence of flavonoids was detected by yellow colouration of the solution that disappears on standing.

\section{Test for Saponins}

To $0.5 \mathrm{~g}$ of each plant extracts $5 \mathrm{ml}$ of distilled water was added in test tubes. The solution was shaken vigorously and observed for a stable persistent froth. The frothing was mixed with 3-4 drops of olive oil and again shaken vigorously after that it was observed for the formation of emulsions.

\section{Test for Tannins}

About $0.5 \mathrm{~g}$ of each plant extracts was boiled in $10 \mathrm{ml}$ of water in each test tube and then filtered. Then few drops of $0.1 \%$ ferric chloride was added and observed for brownish-green or a blue-black colour formation which indicate the presence of tannins.

\section{Test for Phenols (Ferric chloride test)}

Small quantity of extract was dissolved in $2 \mathrm{ml}$ of distilled water, and in to it few drops of $10 \%$ aqueous ferric chloride solution were added. A blue or green colour was produced which indicating the presences of phenols.

\section{Test for Alkaloids}

$0.2 \mathrm{~g}$ of plant extracts were diluted to $10 \mathrm{ml}$ with acid alcohol. It was boiled and filtered. To $5 \mathrm{ml}$ of the solution $2 \mathrm{ml}$ of dilute ammonia was added then $5 \mathrm{ml}$ of chloroform was added to it and shaken gently. In this solution mixture $10 \mathrm{ml}$ of acetic acid was added. This was divided into two portions. The upper layer was discarded; Draggendorff's reagent was added to the other layer. The formation of reddish-brown precipitate with Draggendorff's reagent was regarded as positive for the presence of alkaloids.

\section{Test for Anthraquinones}

$0.2 \mathrm{~g}$ of each of the plant extracts was boiled with $10 \mathrm{ml}$ of $\mathrm{H}_{2} \mathrm{SO}_{4}$ and was shaken with $5 \mathrm{ml}$ of chloroform. The chloroform layer was pipetted into another test tube and $1 \mathrm{ml}$ of dilute ammonia was added. The resulting solution was observed for colour change.

\section{Test for Cardiac Glycosides (Keller-Killiani Test)}

$0.2 \mathrm{~g}$ of each of the plant extracts was mixed with $5 \mathrm{ml}$ of distilled water. $2 \mathrm{ml}$ of glacial acetic acid containing one drop of ferric chloride solution was added to each extract. This was underlayed with $1 \mathrm{ml}$ of conc. $\mathrm{H}_{2} \mathrm{SO}_{4}$. A brown ring at the interface indicated the presence of a deoxy-sugar characteristic of cardenolides. A violet ring appeared below the brown ring, while in the acetic acid layer a greenish ring may formed just above the brown ring that gradually spread throughout this layer.

\section{DETERMINATION OF TOTAL PHENOLIC CONTENT}

The total phenolic content of different extracts of rhizome of Alpinia galanga and leaves of Eryngium foetidum was evaluated using a method 
described by Kim et al. 2003. ${ }^{17}$ According to this, $0.5 \mathrm{ml}$ of extract was added to $4.5 \mathrm{ml}$ of distilled water and then $0.5 \mathrm{ml}$ of Folin Ciocalteu reagent was added to it. After mixing, the mixture was maintained at room temperature for 5 minutes followed by the addition of $5 \mathrm{ml}$ of 7\% sodium carbonate and $2 \mathrm{ml}$ of distilled water in to the mixture. After mixing the solution was incubated for 90 minutes at $23^{\circ} \mathrm{C}$. The absorbance was measured by spectrophotometer at $750 \mathrm{~nm}$. The total phenolic content was expressed in $\mathrm{mg} / \mathrm{g}$ of Gallic acid equivalent, as standard. Determination of total phenolic content was performed in triplicate.

\section{DETERMINATION OF TOTAL FLAVONOID CONTENT}

The flavonoids content of different extracts of rhizome of Alpinia galanga and leaves of Eryngium foetidum was measured based on methods described by Ebrahimzadeh et al. 2008. ${ }^{18}$ According to this method, 0.5 $\mathrm{ml}$ of each extracts was mixed with $1.5 \mathrm{ml}$ of methanol and then 0.1 $\mathrm{ml}$ of $10 \%$ aluminium chloride was added, followed by the addition of $0.1 \mathrm{ml}$ of $1 \mathrm{M}$ potassium acetate and then $2.8 \mathrm{ml}$ of distilled water was added to the total mixture. Then mixture was incubated for 30 minutes at room temperature. The absorbance of the reaction mixture was measured at $415 \mathrm{~nm}$ in spectrophotometer. The total flavonoids content was expressed in mg/g of Quercetin equivalent, as standard. All the determination was perform in triplicate.

\section{DETERMINATION OF DPPH (1,1-DIPHENYL- 2-PICRILHYDRAZYL) RADICAL SCAVENGIN ACTIVITY}

The DPPH radical scavenging activity of different extracts of rhizome of Alpinia galanga and leaves of Eryngium foetidum were determined using the method proposed by Von Gadow et al. $1997 .{ }^{19}$ In this, $50 \mu \mathrm{l}$ of samples of each extracts was placed in separate cuvettes, then in to it 2 $\mathrm{ml}$ of $6 \times 10^{-5} \mathrm{M}$ methanolic solution of DPPH radical was added immediately and absorbance was measured immediately at $517 \mathrm{~nm}$. Then after 16 minutes of incubation decrease in absorbance was again measured for the entire samples. Methanolic solution of Ascorbic acid of $1 \mu \mathrm{l} / \mathrm{mg}$ concentration was used as standard. All the determination was performed in triplicates. The DPPH Radical Scavenging Activity was measured in percentage of reduction of the colour. The percentage inhibition of the DPPH radical by the sample extracts was calculated by the formula suggested by Yen and Duh $1994 .{ }^{20}$ Control was taken at time zero that mean, before the antioxidant present in plant extracts starts its activities.

$$
\% \text { inhibition }=\left\{\left(\mathrm{A}_{\mathrm{C}(0)}-\mathrm{A}_{\mathrm{A}(\mathrm{t})}\right) / \mathrm{A}_{\mathrm{C}(0)}\right\} \times 100
$$

Where, $\quad \mathrm{A}_{\mathrm{C}(0)}=$ Absorbance of control at time, $\mathrm{t}=0$ minute. $\mathrm{A}_{\mathrm{A}(\mathrm{t})}=$ Absorbance of antioxidant at time, $\mathrm{t}=16$ minute.

\section{METAL CHELATING ACTIVITY}

The metal (ferrous ion) chelating activity by different extracts of rhizome of Alpinia galanga and leaves of Eryngium foetidum were estimated by a method suggested by Dinis et al. ${ }^{21}$ with minor modification. In this, about $100 \mu \mathrm{l}$ the each plant part extracts samples were added to $50 \mu \mathrm{l}$ solution of $2 \mathrm{mM} \mathrm{FeCl}$, Then the addition of $200 \mu \mathrm{l}$ of $5 \mathrm{mM}$ ferrozine started the reaction and then the mixture was shaken vigorously and left at room temperature for 10 minutes. Absorbance for reduction of colouration of the solution by each samples were measured at $562 \mathrm{~nm}$ in spectrophotometer. EDTA solution in place of sample extracts was taken as positive control and reagent mixture without sample was used as negative control. The metal chelating activity is expressed in percentage reduction of colour. All the determination was performed in triplicate.
The metal chelating capacities of the extracts were evaluated using the following equation:

$$
\text { Metal chelating capacity }(\%)=\left[\left(\mathrm{A}_{0}-\mathrm{A}_{1}\right) / \mathrm{A}_{0}\right] \times 100
$$

Where, $A_{0}=$ absorbance of the negative control, $\mathrm{A}_{1}=$ absorbance of the sample extracts.

\section{ANTI-DIABETIC ACTIVITY ASSAY (IN VITRO)}

Anti-diabetic potential of verious extracts of rhizome of Alpinia galanga and leaves of Eryngium foetidum were assay in vitro by a method proposed by Prabhakar et al. 2013.22 The in vitro anti-diabetic activity was determined by assaying the inhibitory activity of enzyme $\alpha$-amylase which involves in the breakdown of starch to produce glucose. In this method, $1 \mathrm{ml}$ of extracts was added to $1 \mathrm{ml}$ of the enzyme $\alpha$-amylase in a test tube and incubated for 10 minuts at $37^{\circ} \mathrm{C}$. Then $1 \mathrm{ml}$ of $1 \%$ starch solution was added into it and again incubated for 15 minutes at $37^{\circ} \mathrm{C}$. Then $2 \mathrm{ml}$ DNSA reagent was added in to it, in order to terminate the reaction. The reaction mixture was then incubated in boiling water bath for 5 minutes, and then allows it to cool at room temperature. The absorbance of the reaction mixture was then measure at $546 \mathrm{~nm}$ in spectrophotometer. The standard (control) of the reaction without the extract represents the $100 \%$ enzyme activity. The \% age inhibition of enzyme activity of $\alpha$-amylase was determined by:

$$
\% \text { age inhibition of } \mathbf{a}-\text { amylase }=\frac{\begin{array}{l}
\text { Enzyme activity } \\
\text { of control - } \\
\text { Enzyme activity of }
\end{array}}{\text { Enzyme activity of control }} \cdot 100
$$

\section{ANTIMICROBIAL SCREENING}

\section{Well diffusion method}

The antimicrobial activity of the extracts was determined by Kirby-Bauer Method in agar well diffusion. ${ }^{23}$ In this method initially the stock cultures of bacteria were revived by inoculating in broth media and grown at $37^{\circ} \mathrm{C}$ for 18 hours in incubator. Then agar plates of the Muller Hilton's Agar media were prepared. Each plate was inoculated by 18 hours fresh bacterial suspension $\left(10^{5}-10^{6}\right.$ colony forming unit "CFU"/ml) or fresh bacterial culture by swabbing evenly on the surface of solid agar media. After 20 minutes, wells of $6 \mathrm{~mm}$ diameter were made in solid agar medium with the help of gel puncher and filled with $50 \mu \mathrm{l}$ of various test samples i.e. DMSO dissolved solvent extracts of rhizome part of the plant A. galanga and leaf of E. foetidum. The positive control wells were filled with Amikacin 30 (Standard drug). All the plates were incubated at $37^{\circ} \mathrm{C}$ for 24 hours and then during observation after 24 hours, the diameter of zone of inhibition was measured in millimetre. All the equipments used like media, Petri plates, cotton swab etc. must be sterilised before performing the experiments. As well as proper labelling of the petri plates must be done before performing. All the determination of antibacterial activities of plant extracts were also done in triplicates.

\section{STATISTICAL ANALYSIS}

The results are represented as mean of three replicates followed by standard deviation i.e. Mean \pm SD. The data were subjected to student t-test analysis and the significance of the difference was determined by Graph pad. $P$-value $<0.05$ were considered to be significant. 
Table1: Antioxidant activity of various extracts of rhizome of Alpinia galanga and leaves of Eryngium foetidum is given below

\begin{tabular}{cccc}
\hline \multirow{2}{*}{ Tests } & $\begin{array}{c}\text { Solvent of } \\
\text { extracts }\end{array}$ & \multicolumn{2}{c}{ Antioxidant Present in Plant Species } \\
\cline { 3 - 4 } Total & Methanolic & $37.12 \pm 0.39$ & $50.23 \pm 0.89$ \\
Phenolic & Ethanolic & $49.42 \pm 0.38$ & $55.34 \pm 0.43$ \\
Content & Aqueous & $21.77 \pm 0.73$ & $21.74 \pm 0.57$ \\
Total & Methanolic & $51.76 \pm 1.28$ & $77.24 \pm 0.67$ \\
Flavonoid & Ethanolic & $56.36 \pm 1.35$ & $85.02 \pm 1.57$ \\
Content & Aqueous & $31.71 \pm 1.25$ & $35.58 \pm 1.67$ \\
DPPH Radical & Methanolic & $34.64 \pm 0.62$ & $31.55 \pm 0.76$ \\
Scavenging & Ethanolic & $37.32 \pm 0.14$ & $51.44 \pm 0.23$ \\
Activity & Aqueous & $22.57 \pm 0.11$ & $18.85 \pm 0.33$ \\
Meta & Methanolic & $49.97 \pm 1.05$ & $45.15 \pm 1.02$ \\
Chelating & Ethanolic & $44.70 \pm 0.96$ & $36.09 \pm 0.73$ \\
Activity & Aqueous & $26.20 \pm 1.31$ & $16.20 \pm 0.51$ \\
\hline
\end{tabular}

Values represent mean $\pm \mathrm{SD}$ of triplicate, ${ }^{\star}$ Significant at $p<0.05$.

\section{RESULTS AND DISCUSSION}

The different solvents extracts of Alpinia galanga and Eryngium foetidum exhibited presence of all the phytochemicals tested and varying degree of antioxidants activity in vitro. Flavanoids, phenols, saponins, tannins, anthocyanines, sterols, triterpenoids and anthraquinones were found to be the most common phytochemicals in both the plants. These findings suggest that these plants could be a promising source of bioactive compounds having therapeutic potentials.

Both the plants showed comparable phytochemicals, antioxidant, antibacterial and antidiabetic potential (Tables 1-3).

These results indicate that these plant extracts could be a potential source of natural antioxidants as well as they have promising antidiabetic and antibacterial potentials.

\begin{tabular}{|c|c|c|c|}
\hline \multirow{2}{*}{$\begin{array}{c}\text { Test } \\
\text { Performed }\end{array}$} & \multirow{2}{*}{$\begin{array}{c}\text { Solvent of } \\
\text { extracts }\end{array}$} & \multicolumn{2}{|c|}{ Percentage inhibition of a-amylase } \\
\hline & & Alpinia galanga & Eryngium foetidum \\
\hline a-amylase & Methanolic & $71.27 \pm 0.54$ & $46.02 \pm 0.55$ \\
\hline inhibition & Ethanolic & $54.44 \pm 0.83$ & $52.20 \pm 0.76$ \\
\hline activity & Aqueous & $41.73 \pm 0.63$ & $30.12 \pm 0.67$ \\
\hline
\end{tabular}

Values represent mean $\pm \mathrm{SD}$ of triplicate, ${ }^{\star}$ Significant at $p<0.05$.

Table 3: Antibacterial activity various extracts of rhizome of Alpinia galanga and leaves of Eryngium foetidum with diameter of zone of inhibition in millimetre

\begin{tabular}{|c|c|c|c|c|}
\hline \multirow[b]{2}{*}{ Bacterial Strain } & \multirow{2}{*}{$\begin{array}{c}\text { Zone of inhibition (mm) } \\
\text { by Amikacin30 } \\
\text { (Positive Control) }\end{array}$} & \multirow[b]{2}{*}{ Solvent of extracts } & \multicolumn{2}{|c|}{ Diameter of zone of inhibition (in $\mathrm{mm}$ ) } \\
\hline & & & Alpinia galanga & Eryngium foetidum \\
\hline \multirow[t]{3}{*}{ Bacillus flexus } & $33.50 \pm 3.54$ & Methanolic & $12.1 \pm 0.53$ & $12.9 \pm 0.42$ \\
\hline & & Ethanolic & $13.5 \pm 0.35$ & $12.0 \pm 0.80$ \\
\hline & & Aqueous & $10.5 \pm 0.71$ & $13.0 \pm 1.32$ \\
\hline \multirow[t]{3}{*}{ Bacillus subtilis } & $26.00 \pm 2.83$ & Methanolic & $11.0 \pm 0.56$ & $13.0 \pm 0.35$ \\
\hline & & Ethanolic & $12.5 \pm 0.35$ & $8.0 \pm 1.0$ \\
\hline & & Aqueous & $8.0 \pm 1.41$ & $12.0 \pm 1.8$ \\
\hline \multirow[t]{3}{*}{ Bacillus megaterium } & $22.50 \pm 2.12$ & Methanolic & $15.05 \pm 0.62$ & $13.06 \pm 0.54$ \\
\hline & & Ethanolic & $12.5 \pm 0.35$ & $17.0 \pm 0.50$ \\
\hline & & Aqueous & $4.0 \pm 1.41$ & $7.0 \pm 1.00$ \\
\hline \multirow[t]{3}{*}{ Pseudomonas oleovorans } & $21.5 \pm 0.71$ & Methanolic & $14.06 \pm 0.43$ & $12.0 \pm 1.0$ \\
\hline & & Ethanolic & $8.5 \pm 0.71$ & $9.0 \pm 1.3$ \\
\hline & & Aqueous & ------- & -------- \\
\hline \multirow[t]{3}{*}{ Klebsiella pneumoniae } & $29.5 \pm 0.71$ & Methanolic & & \\
\hline & & Ethanolic & $8.0 \pm 1.41$ & $7.0 \pm 0.5$ \\
\hline & & Aqueous & ------- & -------- \\
\hline \multirow[t]{3}{*}{ Salmonella enterica } & $27.0 \pm 1.41$ & Methanolic & $13.0 \pm 0.05$ & ------- \\
\hline & & Ethanolic & $13.5 \pm 1.12$ & $13.0 \pm 1.1$ \\
\hline & & Aqueous & $11.5 \pm 4.24$ & $15.0 \pm 0.5$ \\
\hline \multirow[t]{3}{*}{ Staphylococcus aureus } & $27.0 \pm 4.24$ & Methanolic & $12.03 \pm 1.30$ & $14.0 \pm 0.7$ \\
\hline & & Ethanolic & $11.0 \pm 0.71$ & $10.0 \pm 1.0$ \\
\hline & & Aqueous & $9.05 \pm 0.71$ & ------- \\
\hline \multirow[t]{3}{*}{ Escherichia coli } & $23.0 \pm 1.41$ & Methanolic & $4.08 \pm 1.40$ & $5.06 \pm 1.27$ \\
\hline & & Ethanolic & $7.04 \pm 1.10$ & $4.56 \pm 1.04$ \\
\hline & & Aqueous & ------- & -------- \\
\hline
\end{tabular}

Values represent mean $\pm \mathrm{SD}$ of triplicate. ${ }^{\star}$ Significant at $p<0.05$. 


\section{CONCLUSION}

Results of present study showed that the plant extracts have strong antioxidant, antidiabetic and antibacterial activities. The highest scavenging activity was seen in E. foetidum ethanolic extract, highest alpha amylase enzyme inhibition in A. galanga methanolic extract. E. foetidum contained higher flavonoids as well as phenolics contents than galanga. The highest was seen in ethanolic E. foetidum and lowest in A. galanga aqueous. But in terms of metal chelating activity, A. galanga extracts showed more than E. foetidum. The ethanolic extract of galanga was also advantageous as an antioxidant in food due to its mild odour compared with the essential oil. This knowledge of the phytochemical constituents of these plants would be valuable in future in order to discover the herbal folkloric remedies in low cost and high efficacy. Further studies are required to isolate active compounds of these extracts to elucidate medicinal potential of individual active ingredients which may give a promising drug molecule to be served for managing oxidative stress and related disorders. This will help to develop new, effective, safe and affordable herbal medicine for the treatment of diabetics and other oxidative stress related disorders.

\section{ACKNOWLEDGEMENT}

The authors are grateful to Lovely School of Biotechnology and Bioscience for providing the facilities for this research work.

\section{CONFLICT OF INTEREST}

None.

\section{ABBREVIATION USED}

CFU: Colony Forming Unit; MTCC: Microbial Type Culture Collection.

\section{REFERENCES}

1. Yumnam JY and Tripathi OP. Traditional knowledge of eating raw plants by the Meitei of Manipur as medicine/ nutrient supplement in their diet. Indian Journal of Traditional Knowledge. 2012;11(1):45-50.

2. Ames BN. Dietary carcinogens and anticarcinogens-oxygen radicals and degenerative diseases. Science.1983;221(4617):1256-64.

3. Horton JW. Free radicals and lipid peroxidation mediated injury in burn trauma: the role of antioxidant therapy. Journal of Toxicology. 2003;189:75-88.

4. Chudiwal AK, Jain DP, Somani RS. Alpinia galangal Willd.-An overview on phyto-pharmacological properties. Indian Journal of Natural Products and Resources. 2010;1(2):143-149.

5. Jaju SB, Indurwade NH, Sakarkar DM, Fuloria NK, MDA, Das S and Basu SP. Galangoflavonoid Isolated from Rhizome of Alpinia galanga (L) Sw (Zingiberaceae). Tropical Journal of Pharmaceutical Research. 2009;8(6):545.

6. Singh YR and Kalita JC. Effects of Methanolic Extract of Alpinia galanga from
Manipur (India) on Utrerus of Ovariectomised C3H Albino Mice. International Research Journal of Pharmacy. 2012;3(5):423-7.

7. Srividya AR, Dhanabal SP, Misra VK and Suja G. Antioxidant and Antimicrobial Activity of Alpinia officinarum. Indian Journal Pharmaceutical Sciences. 2010;72 (1):145-8.

8. Srividya AR, Dhanabal SP, Satish kumar MN, Parth Kumar $H$ and Bavadia. Antioxidant and antidiabetic activity of Alpinia galangal. International Journal of Pharmacognosy and Phytochemical Ressearch. 2010;3(1):6-12.

9. Bhavana GP, Chandrika R and Saraswathi KJ. Quantitative determination of secondary compounds in populations of Eryngium foetidum L. from India. International Journal of Current Science. 2013;9:24-8.

10. Mohammad Amin Shavandi, Zahra Haddadian and Mohd Halim Shah Ismail Eryngium foetidum L. Coriandrum sativum and Persicaria ordorata L: A Review. Journal of Asian Scientific Research. 2012;2(8):410-426.

11. Wong W. Some folk medicinal plants from Trinidad. Economic Botany. 1976;30:104-42.

12. Min BR, Pinchak WE, Merkel R, Walker S, Tomita G and Anderson RC. Comparative antimicrobial activity of tannin extract from perennial plants on mastitis pathogens. Scientific Research and Essay. 2008;3(2):066-073.

13. Daniel Modnicki and Maciej Balcerek. Estimation of total polyphenols contents in Ocimum basilicum L., Orgianum vulgare L. and Thymus vulgaris L. commercial samples. Herba Polinica Journal. 2009;55(1):35-42

14. Mekhora C, Muangnoi1 C, Pimjai C, Saovaros S, Kaimuk C and Siriporn T. Eryngium foetidum Suppresses Inflammatory Mediators Produced by Macrophages. Asian Pacific Journal of Cancer Prevention. 2012;13:121-7.

15. Fatope AO, Ibrahim $\mathrm{H}$ and Takeda $\mathrm{Y}$. Screening of higher plants reputed as pesticides using brine shrimp lethality bioassay. International Journal of Pharmacognosy. 1993;31(4):250-6.

16. Ayoola GA, Coker HAB, Adesegun SA, Adepoju-Bello AA, Obaweya K, Ezennia EC and Atangbayila TO. Phytochemical Screening and Anti-oxidant Activities of some selected Medicinal Plants used for Malaria Therapy in South-Western Nigeria. Tropical Journal of Pharmaceutical Research. 2008;7(3):1019-24.

17. Kim DO, Jeong SW and Lee CY. Antioxidant capacity of phenolic phytochemicals from various cultivars of plums. Food Chemistry. 2003;81(3):321-326.

18. Ebrahimzadeh MA, Pourmorad F and Bekhradnia AR. Iron chelating activity, phenol and flavonoid content of some medicinal plants from Iran. African Journal of Biotechnology. 2008;7(18):3188-92.

19. Von Gadow A, Joubert E and Hansmann CF. Comparison of antioxidant activity of aspalathin with that of other plant phenols of Rooibosed tea (Aspalathon linearis), a tocopherol, BHT, and BHA. Journal of Agricultural and Food Chemistry. 1997;45(3):632-8.

20. Yen GC and Duh PD. Scavenging effect of methanolic extracts of peanut hulls on free-radical and active oxygen species. Journal of Agricultural and Food Chemistry. 1994;42(3):629-32.

21. Dinis TCP, Madeira VMC and Almeida LM. Action of phenolic derivatives (acetoaminophen, salycilate and 5-aminosalycilate) as inhibitors of membrane lipid peroxidation and as peroxyl radical scavengers. Archives of Biochemistry and Biophysics. 1994;315(1):161-9.

22. Prabhakar VK, Jaidka A and Singh R. In vitro study on alpha amylase inhibitory activity and phytochemical screening of few Indian medicinal plant having antidiabetic properties. International Journal of Scientific and Research Publications. 2013;3(8):2250-3153.

23. Kirby MDK, Bauer RW, Sherris JC and Turck M. Antibiotic Susceptibility Testing by Standard Single Disc Diffusion Method. American Journal of Clinical Pathology. 1996;45:493-6. 
PICTORIAL ABSTRACT

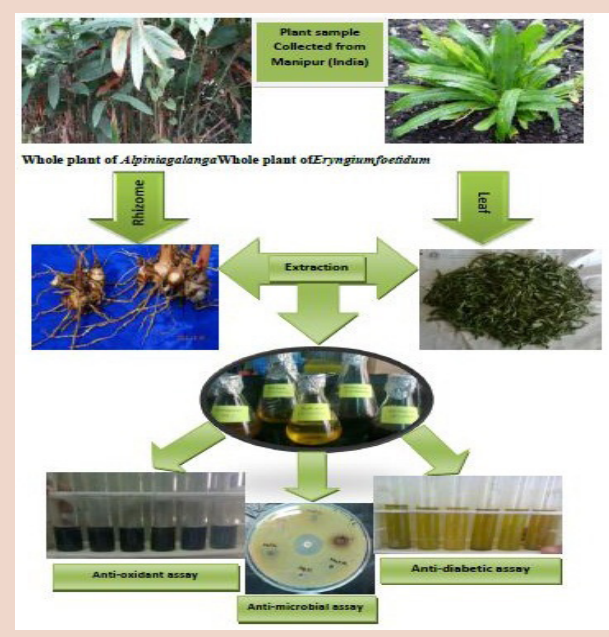

\section{SUMMARY}

- Alpinia galanga and Eryngium foetidum are two commonly used traditional aromatic plants from Manipur.

- Both the plant shows similar DPPH scavenging and metal chelating activity

- Can be used as herbal remedies for the treatment of diabetes mellitus as well as managing oxidative stress and oxidative stress related disorders.

\section{ABOUT AUTHORS}

Dr. Tabarak Malik: Having an extensive record of teaching Specialty Nurses, Dentists, MBBS, M Phil, post graduates in Biochemistry, Microbiology, Life Sciences and Biotechnology. He is member of editorial board and reviewer in many reputed journals. He has authored more than 20 research articles in national and international journals and two books of international reputes.

Devendra Kumar Pandey: Assistant Professor, Department of Biotechnology, School of Biosciences, Lovely Professional University, India. He has authored more than 25 research articles in national and international journals and co-authored book of international reputes.

Priyanka Roy: Junior Research Fellow, Defence Research and Development Organisation (DRDO), Defence Institute of Bio Energy Research (DIBER), Haldwani, Uttarakhand, India.

Annie Okram: Department of Biotechnology, School of Biosciences, Lovely Professional University, PhagwaraIndia 